\title{
Bundling in the Australian Telecommunications Industry
}

\author{
Franco Papandrea ${ }^{\dagger}$, Natalie Stoeckl ${ }^{\dagger}$ and Anne Daly ${ }^{\ddagger}$ \\ ${ }^{\dagger}$ Communications and Media Policy Institute, University of Canberra \\ ${ }^{\ddagger}$ Division of Management and Technology, University of Canberra
}

\begin{abstract}
This article considers some of the implications for social welfare of bundling in the Australian telecommunications industry. The practice of bundling-offering two or more products for sale as a single package-is a strategy used in many industries. Although common, there are circumstances when the practice can be used anti-competitively. Yet bundling does not always harm consumers; at times, the practice benefits both consumers and producers, and it can even advantage consumers to the detriment of producers. The general literature on bundling suggests that its effect on social welfare depends on several factors such as market structure, the elasticity of demand for the products, the marginal cost of production, economies of distribution and the use of complex menus. We consider these factors when assessing the likely welfare effects of bundling in the Australian telecommunications industry, concluding that the potential effects of bundling on competition and the information costs imposed on consumers by complex menus of services seem the most significant considerations for social welfare. It is desirable that regulatory authorities monitor developments closely, although heavy-handed regulation of bundling seems undesirable.
\end{abstract}

\footnotetext{
* We would like to thank the Department of Communications, IT and the Arts for a grant to undertake the research for this project; and participants at the Communication Policy Research Forum and the School of Economics and Marketing, University of Canberra research workshop for valuable comments. Finally we would like to thank the two anonymous referees for their comments.
}

\section{Introduction}

The practice of bundling-offering two or more products for sale as a single package - is a strategy used in many industries. Although it is a common feature of the supply of telecommunication services in Australia, there are circumstances when bundling can be used anticompetitively. For this reason, the practice may attract close scrutiny from regulatory bodies. Yet bundling does not always advantage sellers to the detriment of consumers; there are situations when the practice can advantage both consumers and suppliers, and other cases when the practice may advantage consumers at the expense of suppliers.

From a regulatory perspective, the primary concern with bundling is that a dominant supplier may use the strategy anti-competitively. In relation to telecommunications services, the practice of bundling falls largely under the purview of part XIB of the Trade Practices Act, particularly section $51 \mathrm{AJ}(2)$, which notes that:

A carrier or carriage service provider engages in anti-competitive conduct if the carrier or carriage service provider:

(a) has a substantial degree of power in a telecommunications market; and

(b) either:

(i) takes advantage of that power with the effect, or likely effect, of substantially lessening competition in that or any other telecommunications market; or

(ii) takes advantage of that power, and engages in other conduct on one or more occasions, with the combined effect, or likely combined effect, of substantially lessening 
competition in that or any other telecommunications market.

The legislative focus, therefore, appears to be on whether or not bundling has the effect of substantially lessening competition.

In this article, in addition to a qualitative assessment of the competition effects (and related regulatory implications) we seek to provide an insight into the likely effect on endusers of bundled services, taking a broad set of factors (such as cost effects, price-menu effects) into consideration. The bundling of network elements and other services sold to competitors is subject to the access provisions of the Trade Practices Act 1974 and raises issues beyond the scope of this study.

Finally, it is important to carefully define our terms. 'Bundling' takes place when goods or services that could be sold separately are sold as a package. We follow the lead of other researchers in the field, using these terms:

- pure bundling: goods and/or services are sold only as bundles;

- mixed-bundling: goods and/or services are sold both separately and as a bundle; and

- unbundling: goods and/or services are sold separately.

The article is structured as follows. Section 2 presents an overview of the more common examples of bundled telecommunications services that suggest widespread use of the practice in the telecommunications industry. In Section 3, we examine the way in which bundling affects welfare. Section 4 follows with a discussion of the regulatory implications of bundling in the Australian telecommunications industry from the perspective of end-users. In Section 5, we provide some tentative conclusions on the desirability or otherwise of regulatory intervention.

\section{Bundling in the Australian Telecommunications Industry}

The Telecommunications Act 1997 introduced open competition in the Australian telecommunications industry. In spite of the competition, a partially privatised Telstra (the previously government-owned monopolist provider) remains the dominant supplier in most markets (mobile telephony is an exception). None of the markets, other than perhaps Internet services, could be labelled as being near perfect competition. In most markets, an oligopoly structure pertains. At 30 June 2001, membership of the Telecommunications Industry Ombudsman (TIO) was made up of 59 carriers, 90 telephone service providers, 51 providers of both telephone and Internet services, and 889 Internet service providers (TIO 2001, p. 21). These numbers are continually changing.

Market shares in different segments of the retail telecommunications market during mid2000 are summarised in Table 1. The table highlights the dominance of Telstra in the access market and the local call market. In the newer areas of the industry such as mobile

Table 1 Competition in the Telecommunications Industry, 2000 (per cent)

\begin{tabular}{|c|c|c|c|}
\hline & Telstra & Optus & Other \\
\hline Local retail telephony market (access lines) ${ }^{\mathrm{a}}$ & 85 & 3 & $11^{\mathrm{b}}$ \\
\hline National long distance & 75 & 16 & 9 \\
\hline International & 48 & 18 & 34 \\
\hline Wholesale mobile & 46 & 33 & 21 \\
\hline Internet & 24 & 8 & 68 \\
\hline
\end{tabular}

Notes: (a) Data were also presented on the basis of revenue and show a similar story.

(b) Includes resale of Telstra's basic access lines including those resold to Optus. Telstra owns 95 per cent of the access lines.

Source: Productivity Commission (2001, ch. 4).

(C) 2003 The University of Melbourne, Melbourne Institute of Applied Economic and Social Research 
phones and the Internet, Telstra's share of the market fell below 50 per cent.

Bundling has always been a feature of telecommunications markets. Under the government monopoly, the only choice available to customers was a telephone service that bundled together the telephone handset, line rental, maintenance, and access to local, long distance and international calls. Today, customers can make different choices for each of

Table 2 Examples of Bundling by Major Telecommunications Carriers, 2001

Service Consumer bundles offered

Telstra

Fixed service Offers different bundles combining higher access charges with lower call costs, options of different long distance capped rates, capped call rates to Telstra mobile services at night and international call options. An additional discount is provided to customers who receive and pay their telephone accounts online. Additional options include:

(i) 5 per cent discount on eligible call or Internet charges if two of fixed, mobile and Internet services are on single bill; 10 per cent if all three are on a single bill, plus an annual bonus of 15 per cent of eligible discounted charges.

(ii) 25 per cent discount on eligible calls between fixed and mobile services on a single bill (50 per cent discount applicable if mobile phones are on higher monthly rates).

Mobile service At least 17 different plans combining monthly charges with different peak and off-peak call rates with a choice of discounted mobile phones for fixed subscription period contract. Group plan available for two or more mobile services combined on one bill featuring discounted subscription rates for second or additional service and special call rates.

Internet Several plans incorporating monthly access charges and hourly usage charges above a given level of monthly usage hours (some with unlimited hours) that varies with the access charge.

Optus

Fixed service Three different packages combining equipment with varying access and usage charges to customers in areas connected to the Optus pay TV cable network. Preselection of Optus for long distance calls (STD and international) is a condition of service. Additional features may be added to the service. In other areas, customers pre-selecting Optus for long-distance calls are offered resale of Telstra local services on one bill. STD customers offered flat rates, capped per call charge and 'free time' on long distance calls and calls to mobile phones connected to any Australian mobile network.

Mobile service Over 20 plans combining monthly charges with different peak and off-peak call rates with a choice of discounted mobile phones for fixed subscription period contracts. Limited free calls off- peak and weekends to mobiles on the same network.

Internet Several plans incorporating monthly access charges with hourly usage charges above a given level of monthly usage hours (some with unlimited hours) that varies with the access charge. A five hour free bonus per month provided to subscribers to other Optus services (a reduced monthly subscription rate applied to unlimited hours plans).

Vodafone

Mobile service Seven packages combining monthly charges with different peak and off-peak call rates with a choice of discounted mobile phones for fixed subscription period contracts. Limited free calls off peak to mobiles on the same network and to fixed telephones.

Internet Various plans incorporating monthly access charges and hourly usage charges above a given level of monthly usage hours that varies with the access charge.

AAPT

Fixed service Bundle combining local call service (line rental and calls) with preselection for long distance calls and calls to mobile services.

Mobile service Twenty or more packages available. Mobile services are provided through Vodafone or Optus and have similar features to packages offered by those carriers.

Internet Two plans, one with unlimited hours of access for a fixed monthly subscription or monthly subscription plus hourly usage rates above 11 hours per month.

Sources: Telstra, Optus, Vodaphone, AAPT web sites and published material.

(c) 2003 The University of Melbourne, Melbourne Institute of Applied Economic and Social Research 
the previously bundled elements. Nonetheless, bundling continues to be a feature of the industry, particularly in relation to new services, and its use as a pricing strategy is widespread.

Bundles may take one of two basic forms. The first is the traditional packaging of two or more goods for sale as a bundle, for example a mobile phone and related calls. The second is the discounting of aggregate expenditure on two or more goods that a customer purchases from a supplier, for example discounts on the total bill for customers who purchase more than one service from a carrier.

Table 2 provides indicative information on the types of bundling practices used by major carriers and service providers operating in the Australian telecommunications market. Generally, the services are offered as mixed bundles giving the consumer a choice of a package or individual components. Both bundling strategies are common. Major carriers involved in both fixed-line and mobile services markets, appear to be seeking to exploit the consumer's preference for a single bill and offer bundles of services in each of the two markets, as well as bundles spanning both markets. Both Optus and AAPT, for example, resell Telstra's local services to provide bundles of local and long distance services. AAPT also resells Optus and Vodafone mobile services. Vodafone, which operates primarily in the mobile market, tends to confine its bundles to that market. The likely welfare effects of these types of bundling are examined below.

\section{The Welfare Effects of Bundling}

The economic welfare effects of an action are normally assessed against the competitive market standard of efficiency that equates prices to short run marginal cost (SRMC). There is an extensive body of theoretical literature on bundling and its welfare effects. We present here a brief summary of some of the key issues that emerge from the theoretical literature. A more detailed survey of literature is provided in $\mathrm{Pa}$ pandrea, Stoeckl and Daly (2000).

Before beginning, it is important to place our summary in context. The broad objective of the Trade Practices Act is to "enhance the welfare of Australians through promotion of competition and fair trading and providing consumer protection' (Australian Competition and Consumer Commission (hereafter ACCC) 2001b, p. 3). To this end, part IV of the Act is directed against anti-competitive behaviour such as misuse of market power but part XIB, as already noted, is specifically directed at anticompetitive behaviour in the telecommunications industry. While part IV focuses on the intention of acts to reduce competition, part XIB has the more stringent test of the effect, or likely effect, of behaviour on competition (see an earlier quote from the Trade Practices Act section 51AJ (2)). In other words, regulatory bodies are primarily interested in bundling because it has the ability to affect welfare by affecting competition. Our interest is, therefore, broader than that of some regulatory bodies; we discuss the 'competition' effects of bundling, but we also discuss other effects.

Overall, the effect of bundling on social welfare is difficult to predict. This is because bundling can affect consumer surplus, producer surplus (of the firm using bundling, and of other firms), the pay-offs and strategies of firms in oligopolistic markets, and the market structure(s) of the bundled goods. The magnitude (and sometimes even direction) of these effects depends on a range of factors including the elasticity of demand, the marginal cost of production, economies of distribution, search costs, the market structure(s) of the bundled goods, and the size of fixed costs relative to total costs, and upon the number of effects occurring simultaneously, and their interaction. Assessment of the welfare implications of bundling, therefore, requires identification of which of these factors are most/least likely to occur and a consideration of their effect on welfare. A summary of the main factors influencing the welfare outcomes of bundling practices is provided in Table 3. For example, where marginal costs are low, bundling may increase welfare and where they are high, it is likely to reduce welfare.

In addition to the factors listed in Table 3 , market structure plays an important role in determining the likely welfare effects of bundling. Its role, however, is a complex one-it is 
Table 3 Key Indicators of Likely Welfare Effects of Bundling

\begin{tabular}{lcc}
\hline & \multicolumn{2}{c}{ Effect on social welfare } \\
\cline { 2 - 3 } Factor & Increase & Decrease \\
\hline Demand & Inelastic & Elastic \\
Marginal cost & Low & High \\
Economies of distribution & Substantial & Few \\
Pricing menus & Simple & Complex \\
Fixed costs & High & Low \\
\hline
\end{tabular}

Source: Papandrea, Stoeckl and Daly (2000).

impossible to make a priori assessments of the likely welfare impacts of bundling in oligopolistic markets without careful consideration of the strategic interaction of firms.

\subsection{Bundling, Demand and Marginal Cost}

Stigler (1963) was the first economist to recognise that when buyers have substantially different valuations for products, a seller may be able to exercise a form of price discrimination and increase profits by selling the products as a bundle, rather than separately. His finding was extended by Adams and Yellen (1976) to show that a multi-product monopolist could further increase profits by offering buyers the choice of purchasing either the bundle or one or more, but not all, of the components separately. In effect, bundling allows firms to engage in price discrimination without needing prior information about the valuation that consumers place on individual goods. This is because it reduces the effective dispersion of consumer tastes (see Schmalensee 1984) and because it is easier to predict consumer valuations for the bundle than for its individual components (Bakos and Brynjolfsson 1998).

This facet of bundling - namely that it reduces the need for market research - is particularly useful in rapidly changing industries, where historical information on consumer purchases is only of limited value in developing an adequate understanding of the direction of change. All suppliers face this problem and they tend to respond to it by changing their selling strategies. In a market with several suppliers, the combined effect of changing seller strategies and changing consumer tastes makes it difficult to determine what might be the best bundle/price combination. As a result, there is an incentive to offer a range of bundles. Faced with a range of bundles, consumers are forced to self-select into the bundle/price combination that they consider best meets their needs. For the supplier, consumer self-selection is desirable because it exploits the pricing discrimination attributes of bundling and captures more consumer surplus than a single bundle.

In a first-best world, pure bundling is less efficient than unbundling, primarily because the practice 'confuses' the price signals to consumers, leading to an over-supply of some goods (Schmalensee 1982; Kahn and Shew 1987). The effects listed in Table 3 indicate that in general, the less elastic is the demand for the bundled goods, the less will be the welfare losses, ceteris paribus. This is because bundling will not increase consumption if demand is inelastic. If consumption remains constant (at some, presumably 'optimal' level), then 'over-consumption' (where marginal benefit is less than marginal cost) cannot occur-irrespective of whether price is greater or less than marginal cost.

In general, bundling is also less likely to generate substantive welfare losses if the bundled products have low marginal costs, ceteris paribus. More specifically, if bundling raises the consumption of a good that costs little to produce, then the cost of 'over-consumption' is low (as when consumers purchase "value meals' at takeaway shops, and do not finish all of their drink). However, if bundling raises the consumption of a good with high marginal costs, then the potential for more substantive welfare losses exists. In this context, marginal 
cost is defined as the additional cost incurred by a firm in producing the extra goods that are demanded in response to the bundling strategy. It is possible (although, perhaps improbable) for bundling to increase demand to the point where producers need to expand capacity. If the extra capacity is only required because of that increased demand, then the longrun increment to costs is an appropriate measure of marginal costs. However, if bundling does not force the upgrading of capital equipment, then SRMC may be a more appropriate measure.

To apply this intuition to the telecommunications industry requires information on the elasticity of demand and marginal cost of supplying services that are typically bundled. This information is not readily available. A summary of the findings of several (mainly nonAustralian) studies of the price elasticity of demand of telecommunications services is provided in Albon, Hardin and Dee (1997). Although the individual estimates vary considerably, there is consistent indication in the studies that demand for fixed access is inelastic (ranging from -0.003 to -0.096 ). The elasticity of demand for other services varied but was generally found to be higher than for fixed access. For the purpose of the intuitive analysis undertaken in this article, the direction of the likely welfare effect of bundling can be gauged from a broad estimate of the elasticity of demand for a service relative to that for fixed access. A relative ranking of the elasticities is provided in 4 . It should be noted that the ranking is intended to provide only an ordinal indi- cation of the elasticities and should not be interpreted as an indication of their relative size (that is, a ranking of 2 indicates that local calls are more elastic than fixed access but is not intended to provide any indication of how much more elastic they are). The table also provides a similar ranking for indicative estimates of marginal costs based on the authors' assessment of the capacity constraints in the supply of the services.

The information in Table 4 can be used to make qualitative assessments of the welfare impacts of bundling. For example, the results suggest that, ceteris paribus, there may be low social welfare costs associated with the bundling of basic fixed access and local calls. This is because the demand for both products is relatively inelastic, hence there will be little 'over-consumption'; the fact that the marginal costs of supplying additional services is relatively high may be irrelevant.

We can also note that, ceteris paribus, the bundling of international and mobile calls is more likely to generate welfare losses than the bundling of fixed access and local calls. This is primarily because the demand for international calls and for mobile telephony is more elastic than the demand for fixed access and local calls. Consequently, bundling is more likely to increase demand for international calls and mobile telephony (to the point where their marginal value is less than their marginal cost) than it is to increase demand for fixed access and local calls. It must be stressed, however, that these two preceding points assume that any other offsetting effects (discussed in more

Table 4 Relative Ranking of Demand Elasticities and of Marginal Costs in Components of the Australian Telecommunications Industry

\begin{tabular}{lcc}
\hline Service & $\begin{array}{c}\text { Price elasticity of demand } \\
(1=\text { most inelastic } ; \text { 4 = most elastic })\end{array}$ & $\begin{array}{c}\text { Marginal cost } \\
(1=\text { lowest } \text { 4 }\end{array}$ highest $)$ \\
\hline Fixed access & 1 & 4 \\
Local calls & 2 & 2 \\
Domestic long distance calls & 3 & 1 \\
International calls & 4 & 2 \\
Fixed to mobile & 3 & 2 \\
Mobile & 3 & 2 \\
\hline
\end{tabular}

Sources: Price elasticities are derived from Albon, Hardin and Dee (1997). Marginal costs are indicative estimates by the authors and reflect their assessment of the capacity constraints in the supply of the services. 
detail below), and/or other market distortions, are negligible.

\subsection{Bundling, Fixed Costs and Economies of Distribution}

SRMC pricing will not achieve full cost recovery for the supply of utility services that typically involve considerable fixed costs. As a result, second-best practices are common (particularly in telecommunications) and it is against these practices that the welfare effects of bundling may need to be judged.

First, where fixed costs are high, the market may be second-best (that is, $P>M C$ ) and bundling may be welfare enhancing. To illustrate, assume that product $\mathrm{A}$ is initially 'underconsumed' $(P>M C)$. It is then bundled with product $\mathrm{B}$-one that is, initially, consumed at an optimal rate. The bundling increases consumption of both goods, generating welfare losses in the market for product $\mathrm{B}$, and welfare gains in the market for product $A$. In some cases, the net welfare effects will be positive (see, for example, Spence (1976, p. 218), who argues that if there are fixed costs and if a firm can price discriminate, then 'the welfare aspects of the product-choice problem are eliminated').

Second, bundling may be welfare enhancing if substantial economies of distribution ${ }^{1}$ are present. The greater the cost savings from bundling, the larger the potential gains to both producer and consumer. Who gets a larger share of these cost savings, depends upon the relative elasticities of demand and supply-the more inelastic is demand relative to supply (or more precisely, marginal cost), the larger the potential gain in consumer surplus relative to the potential gain in producer surplus.

An important characteristic of the telecommunications industry, at least in the past, has been substantial economies of scale in the local network. Consumers of telecommunications services may therefore benefit from bundling of products for this reason. However, some economists have argued that local telecommunications are no longer a natural monopoly (for example, Spulber 1995). In their analysis of telecommunications economics and policy in Australia, Albon, Hardin and Dee (1997) con- clude that there is no firm empirical evidence either supporting or denying the existence of economies of scale. Technological changes and alternative means of supplying services in the local loop further complicate considerations.

Without further research, specifically addressing the current situation, it is difficult to determine to what extent high fixed costs are present. Nonetheless, there is substantial evidence of growing competition in some market segments (particularly the central business districts of Sydney, Melbourne and Brisbane (ACCC 1999)), but not in others (sparsely populated rural areas). This suggests that economies of scale are not a substantial barrier to entry in densely populated urban areas, but may be important in rural areas. The assessment of welfare implications of telecommunications bundling may differ therefore between urban and rural areas. On the basis of this difference, it is possible to conclude that, ceteris paribus, bundling is less likely to be welfare reducing in rural areas than in urban areas.

There are likely to be economies of distribution in telecommunications that may result in consumers benefiting from bundling. One example is billing charges. The cost of sending a customer a bill for two services is not twice the cost of sending a bill for one service. There is also some evidence that consumers prefer one bill for all telecommunications usage, rather than separate bills for different services. Competitors have used this as an argument for the declaration of unbundled access to Telstra's local network (see, for example, ACCC 1999). It is argued that new competitors that are unable to offer a bundle of telecommunications products will be ineffective as real competitors with Telstra. The presence of economies of distribution should increase the social welfare of bundling.

\subsection{Bundling and Price Menus}

The indicators listed in Table 3 suggest that bundling practices which serve to simplify pricing menus are more likely to be welfare enhancing than those which serve to increase their complexity. This is because consumers have expressed a preference for 'one bill', and 
bundling makes such billing possible. Total billing costs may be reduced when the same billing system is used for multiple services. Consumers may also benefit from bundling where it reduces the costs of searching. To the extent that this is so, bundling may therefore increase consumer welfare.

The corollary of course, is that bundling which results in complex price menus may increase the costs of searching for the preferred purchase, thereby reducing consumer welfare. This is because consumers need to obtain information and learn about the quantity, quality and price combinations offered by the various suppliers. Evaluation of the alternatives, particularly when products are bundled, can be a complex task, one made even more difficult by the constant introduction of new products and by deliberate randomised pricing strategies designed to maximise supplier profits. Such strategies reduce the ability of consumers to use experience to better inform their buying decisions.

Many researchers have found evidence to suggest that consumers make systematic errors when attempting to assess the true 'worth' of bundled goods (see Russo 1977; Capon and Kuhn 1982; Australian Communications Authority 1999, p. 10). Generally, this advantages producers at the expense of consumers (Estelami 1999), and in the extreme can lead to complete market failure-as when complex menus are coupled with asymmetric information (see Kephart, Das and MacKie-Mason 1999). Yet this loss of consumer surplus resulting from complex menus may be only a short-run phenomenon. MacKie-Mason, Riveros and Gazzale (1999, p. 1), for example, claim that 'while there is a steep initial learning curve, decision makers rapidly develop an understanding of innovative pricing schemes'.

While research findings indicate that the introduction of competition in the telecommunications industry was followed by a reduction in prices and an extension in the range of services offered, it was also followed by increased complexity of pricing menus. Muir, Jennings and McAnally (1999, p. 124) argue that the existence of price differentials between suppliers suggests: either lack of interest or awareness on the part of consumers of the 'menu' of prices on offer or else the existence of real or perceived disparities in the quality of the services themselves or their supplier. Alternatively, consumers may believe that the effort involved in identifying and evaluating the increasingly complex 'menu' and the complexity of switching service providers or using more than one operator, may exceed the benefits.

While current telecommunications bundling practices have increased the complexity of price menus and may have imposed costs on consumers, it is unclear whether this is more than a feature of the transition from a monopoly to a more competitive structure. In other words, it is possible that as competition matures and consumers become better informed, firms will have incentives to offer simpler menus as a means of drawing customers away from their competitors.

\subsection{Bundling and Market Structure}

One of the prime concerns with the practice of bundling is the possibility that a monopolist in one market may be able to use that position to extend its power into a market for products where it competes with other firms. Oligopolists, in particular, may be prone to use bundling as part of their dynamic strategies. A firm with significant monopoly power can also use bundling as a 'predatory pricing', strategy to substantially lessen competition.

By selling the two goods as a discounted bundle price, the incumbent firm can make it more difficult for rivals producing only one of the goods to enter the market without having to offer a relatively low price on each of the goods (even if the incumbent is not, strictly speaking, using 'predatory pricing'). As demonstrated by Nalebuff (1999), the use of bundling as an entry deterrent is at its most effective when the goods are positively correlated (complements), but it loses its effectiveness when the goods are perfectly negatively correlated in value (substitutes) (note that these are the converse of the conditions for the use of bundling as an effective tool for price discrimination).

When goods are positively correlated consumers buy both goods and single product 
entrants are unable to satisfy the full customer demand. The advantages of bundling as an entry deterrent in such a situation are illustrated in Figure 1, which shows the situation from the point of view of the consumer. Assume that an incumbent is producing two goods (A and $\mathrm{B}$ ) and sells them individually at prices above marginal cost (monopoly pricing). A new entrant is seeking to enter the market with only one of the two goods (say, B) at a price equal to marginal cost (that is, it undercuts the incumbent's price). The incumbent responds by offering the two goods as a bundle at a price equal to the marginal cost of $\mathrm{B}$ plus a discounted price for A (equal to at least its marginal cost), as well as continuing to sell the two goods individually at the original price. From a consumer's perspective, the incumbent's response is equivalent to offering a price below marginal cost for B that the new entrant cannot match. The incumbent, therefore, can deter competition by any single-product entrant without the need to match the individual prices offered by the new entrants and can still extract some of the original monopoly profits.

The incumbent would be able to reduce the extent to which the new entrant can compete for its customers - that is, those purchasing B only would be challenged, but those buying A and B would not be contestable. Of course, in this simple example entry of two or more single-product firms could allow consumers to produce their own bundle of the two goods from two different suppliers and thus erode the advantage of the incumbent. But even then, the consumer would incur a cost in creating the bundle, which would act as an incentive to buy a similarly priced bundle from the incumbent (for example, buying local calls from one provider and long distance calls from another). Also, the incumbent would be able to benefit from any economies of scope that may be available in the production and distribution of the two goods giving it a competitive advantage over single-product producers (for example, use of a common billing system for the two services).

The other form of bundling - that is, discounting-may also have anti-competitive effects, despite the fact that it is usually considered a sign of vigorous competition. For example, if not justified by demonstrable cost savings, discounts on total expenditure on a bundle of products that are complements, including one in which a firm is dominant, could have tying-like effects even though a customer is not compelled to buy the goods as a bundle.

To illustrate, assume that a dominant fixed telephone service supplier offers a 25 per cent discount on eligible calls (in both directions) between the fixed service and a mobile service, which it supplies in a competitive market. If the consumer makes $\$ 10$ worth of calls in each direction his total bill after discount will be $\$ 15$. However, if he buys his mobile services from an alternative carrier who provides a 25 per cent discount on mobile to fixed phone calls, he will only receive a discount on half his calls, that is those made from the mobile phone to a fixed phone. His total bill will be $\$ 17.50$. A competitor who supplies only a mobile service would thus have to offer at least a 50 per cent discount on calls on its mobile services to compete for customers who are purchasing a fixed

Figure 1 Bundling as an Entry Deterrent

\begin{tabular}{|l|c|c|}
\hline Incumbent price of A & \multicolumn{2}{|c|}{ Incumbent price of B } \\
\hline Incumbent price of A & New entrant price of B & \\
\hline \multicolumn{2}{|c|}{ Bundle price (incumbent) } & \\
\hline Implicit price of A & Implicit price of B \\
\hline
\end{tabular}

Purchase of individual goods from incumbent

Purchase of A from incumbent and $\mathrm{B}$ from new entrant

Purchase of bundle from incumbent

(C) 2003 The University of Melbourne, Melbourne Institute of Applied Economic and Social Research 
Table 5 Effects of Expenditure Discount Bundles

\begin{tabular}{|c|c|c|c|c|}
\hline & \multirow{2}{*}{$\begin{array}{l}\text { Bundled } \\
\text { purchase }\end{array}$} & \multicolumn{3}{|c|}{ Unbundled purchase } \\
\hline & & Mobile supplier & Fixed supplier & Total \\
\hline Mobile to fixed (dollars) & 10.0 & 10.0 & na & 10.0 \\
\hline Fixed to mobile (dollars) & 10.0 & na & 10.0 & 10.0 \\
\hline Discount (dollars) & 5.0 & 2.5 & 0.0 & 2.5 \\
\hline Total bill (dollars) & 15.0 & 7.5 & 10.0 & $17.5^{\mathrm{a}}$ \\
\hline $\begin{array}{l}\text { Effective discount on } \\
\text { mobile to fixed (per cent) }\end{array}$ & 50.0 & 25.0 & 0.0 & 25.0 \\
\hline
\end{tabular}

Note: (a) Includes $\$ 10$ expenditure on fixed to mobile calls sourced from supplier of fixed services.

service from the dominant supplier of fixed services. The effects are summarised in Table 5.

There is, however, a particularly interesting twist to the story of 'bundling as an (anti) competitive device': this is a twist, which can occur when new entrants use bundling strategically. In much the same way that an incumbent can use bundling to deter or mitigate the effects of competitive entry, a new entrant could be seeking to secure an advantage over an incumbent whose pricing strategies may be constrained by regulation. Such an advantage, however, will materialise only if the incumbent perseveres with the sale of individual components. If the incumbent responds with its own bundle, strong bundle-to-bundle competition develops and prices are rapidly driven down. The literature suggests that bundling by at least one new entrant frequently provokes strong bundle-tobundle competition, generating a prisoners' dilemma (Economides 1993). Rather than serving to 'substantially lessen competition' and increase firm profits (as might have been the intent of firms), this type of bundling lowers profit, to the advantage of consumers.

\section{Regulatory Implications for the Australian Market}

To the extent that bundling is being used anticompetitively, it will lower consumer surplus while raising producer surplus. However, as discussed in Section 3, oligopoly bundling need not be anti-competitive; rather, it may signal a 'prisoner's dilemma' which advantages consumers at the expense of producers.
Consequently, one needs to consider whether Telstra, as the dominant operator, has attempted to use bundling as a form of predatory pricing to frustrate competition and deter entry; or, whether current bundling is more likely to have originated from new entrants. Empirical information that could be used to assess the motivation for bundling is not readily available. The following assessment, therefore, has had to rely on qualitative analysis guided by general observations of market behaviour.

Telstra is probably the only player in the Australian telecommunications market in a position to use bundling in an anti-competitive manner to maintain its market power or to minimise the impact of competition from new entrants. As the dominant player operating in all telecommunications services markets, Telstra would have had many opportunities to use bundling as a strategy against competitors supplying only a limited range of services. However, Telstra does not appear to have pursued bundling as an aggressive competitive strategy. Indeed, there are several factors suggesting considerable disincentives for Telstra to employ such a strategy.

At least in the early stages of market entry, new entrants have typically supplied localised geographic markets with a limited range of services. Competition with Telstra, therefore, has tended to be localised both in the geographic and product sense. In a completely unregulated market, Telstra could have easily produced a bundle of services including at least one of the services in which it is dominant (for example, local call service). However, services in which Telstra is dominant are subject to price controls 
and related regulation (ACCC 2001a). ${ }^{3}$ Those controls limit Telstra's scope to use bundling to deter competition for several reasons.

Assuming that price controls are based on the cost of supplying a service, any attempt by Telstra to bundle one of its dominant, pricecontrolled, services with another service would clearly signal the implicit price charged for the other services in the bundle. The implicit price is the bundle price less the regulated price for the monopoly service. The inability of competitors to match the implicit price would then signal the likelihood of Telstra cross-subsidising the competitive service with the dominant service. In that event, the ACCC would be quickly alerted to the possibility that Telstra may be employing predatory pricing against competitors. There would be a risk, therefore, that Telstra might find itself facing an investigation, and possibly sanctions, by the ACCC.

Furthermore, it is unlikely that Telstra would be allowed to maintain and exercise its dominance in the current regulatory regime. The access provisions of the Trade Practices Act allow for the declaration of monopoly or bottleneck services to which Telstra must provide access to its competitors on a cost basis. Local carriage services have already been declared by the ACCC for this purpose and so has access to unbundled local loops. These declarations take away much of Telstra's monopoly power in the provision of access to the local loop and the supply of local calls.

In addition to these regulatory-related constraints, Telstra would also face strong pecuniary disincentives to engage in anti-competitive bundling. While a competitor may be operating in a localised market, price regulation precludes Telstra from implementing a localised response to the competitor. ${ }^{4}$ Implicit losses that it may incur from the 'predatory' bundle, therefore, are not confined to the local market subject to competition, but would accrue in all geographic markets. These could be substantial, relative to the potential local gains from anti-competitive bundling, and much more difficult to sustain for extended periods. Furthermore, there may be longer term and ongoing revenue losses. The formula used to control prices has an inbuilt ratchet mechanism that al- lows downwards movements only. Price increases in any year are restricted to movements in the CPI minus a factor for productivity growth. Thus any price reduction on services subject to price control cannot be recouped by subsequent price increases.

New entrants on the other hand, have an incentive to better Telstra's prices for the services they supply. At this stage in the market, Telstra has considerable 'first mover advantage'. For new entrants the chance of success in a market in competition with Telstra is likely to be small, unless they can supply services offering consumers a better price/quality combination than that provided by Telstra. Bundling of services by new entrants in such a situation also serves the purpose of confounding Telstra on the individual price charged for the services. By not knowing how to respond to individual prices and because of the constraints of price controls, the only way for Telstra to match a competitor's offering would be to offer a bundle of its own with similar features.

Another important motivation for new entrants to bundle services is their limited information on consumer tastes and valuations for the services they supply. Bundling allows firms to discriminate on price, even when they do not have information on the consumers' valuations of individual products. Unlike Telstra, new entrants do not have historical consumer expenditure information that can be used as an indicator of trends in consumer tastes and are thus at a comparative disadvantage vis-à-vis consumer preferences. In relative terms, bundling may therefore be more attractive to new entrants than to Telstra.

As noted earlier, bundling also appears to be partly driven by consumer preference for a single bill. New entrants have been purchasing line rental and local call services from Telstra, for resale to customers being supplied with other services. There are anecdotal claims that some carriers are reselling these services at a loss as part of bundle that includes customer pre-selection of the carrier for long distance and international calls.

In the telephony market, the timing of Telstra's bundling tends to suggest that it may be a competitive reaction to the bundling 
strategies of new entrants, with the intention being to mitigate their impact rather than being an anti-competitive manoeuvre to lock out competition. To the extent that this is so, telephony bundling may more likely represent a prisoner's dilemma situation, which is advantaging consumers, than an anti-competitive entry deterrent or predatory pricing strategy.

The markets for other telecommunications products (for example, data/Internet) are much more competitive, and not historically characterised by a dominant firm. To this end, it is possible that Telstra initiatives to bundle the Internet with other telephony services could be an attempt to extend market power. As noted earlier, however, this is difficult to do when the 'other market' is extremely competitive-the leverage argument holds only when analysed in a static context. In major metropolitan markets, competition in the supply of telecommunications services is increasing both through infrastructure investment by carriers and by the impact of regulations providing access to incumbents' declared services and facilities. Such increased competition will reduce the scope for a dominant carrier to use bundling as a leverage mechanism. In other markets, however, competition remains weak and prospects for such bundling could remain a significant factor for consideration. It would appear, therefore, that the best option for policy makers and regulators might be to allow such practices (noting that there are potential consumer gains), subject to regular review to ensure that no single firm is gaining undue market power. It may also be desirable for regulatory authorities with access to industry performance data to commission empirical research so that a better understanding of this issue may be developed.

\section{Conclusion}

The aim of this article has been to consider some of the welfare implications of bundling practices in the Australian telecommunications industry. There are many examples, including packages of services and equipment and a discount for consumers of more than one service. The use of bundling has increased substantially with the introduction both of new services and open competition in the industry in 1997.

Bundling can have different effects on social welfare depending on a number of factors including market structure, the elasticity of demand for the products, the marginal cost of production, economies of distribution and the use of complex menus. The implications of bundling for welfare therefore must be assessed in each individual situation. This requires extensive research to establish empirical estimates of such factors as the elasticity of demand, the marginal cost of supply, fixed costs of supply and the size of the economies of distribution. It also requires an assessment of the welfare costs of complex pricing menus and of the dynamic effects of bundling on market structure.

Bundling considerably increases evaluation costs for consumers. In the context of the Australian telecommunications industry, the implications for social welfare of the development of complex price menus are of particular significance. Complex pricing menus increase the difficulties faced by consumers in choosing the best option for themselves. This almost certainly erodes consumer surplus-either because consumers need to spend considerable time selecting an appropriate bundle, or because they select an inappropriate one, perhaps on the basis of reasoning that the search costs are higher than the premium. One way that regulators could assist consumers would be to provide comparative information on price menus on a standardised basis. A more heavy-handed regulatory approach in this instance would not appear to be warranted, as it could stifle innovation and may prevent the development of welfare-enhancing price menus/bundles.

At this early stage of the development of competition in this market, the dynamic effects of bundling should be the chief focus of concern. If bundling could be shown to have the effect, or likely effect, of substantially lessening competition in any telecommunications market, then the practice would contravene the Trade Practices Act 1974, part XIB. The preliminary conclusions presented here suggest that the current practice of bundling is probably not against the Act. It is more likely to 
reflect a prisoners' dilemma situation where new entrants are forced to develop a bundling strategy in order to compete with the incumbent, Telstra. In turn, Telstra has had to develop bundles in the new markets of mobile telephony and Internet access as bundling emerged as the dominant strategy in those markets. The theoretical literature suggests that bundling need not provide a successful tool for leverage for a monopolist in one market attempting to enter a new competitive market. The literature, however, does suggest that in some oligopoly situations bundling may be used to protect market power against competitive entry in the market for one of the components of the bundle. It seems important, therefore, that developments in a rapidly changing sector such as telecommunications are monitored for any potential long-term adverse effects on competition.

First version received October 2001; final version accepted July 2002 (Eds).

\section{Endnotes}

1. Economies of scope occur when two commodities can be produced by a single firm for less than the cost of two separate firms producing one commodity each. But economies of scope in production do not necessarily imply that it will be cheaper to sell the goods jointly or in a bundle. That is, there is a distinction between economies of scope deriving from joint production, versus those deriving from joint distribution, administration or billing (hereafter referred to as economies of distribution). Although we acknowledge the importance of economies of scope, we are, primarily interested in whether or not the savings can be made if goods are sold as a single package (irrespective of whether or not the goods are produced jointly). Consequently, we focus on economies of distribution.

2. Predatory pricing refers to situations where a firm uses its market power to sacrifice shortterm profits for long-term gain by pricing below cost to deter competitive entry. If proven, such behaviour is subject to severe penalties. However, proof of predatory conduct may be difficult to establish, particularly when bundling is involved.

3. Price controls apply to a basket of services and allow some movement in the relative prices of the components provided the weighted basket price does not increase more than the permitted amount.

4. The local call parity provisions require that the weighted average price of local calls in regional areas is not greater than the comparable price of local calls in metropolitan areas for both business and residential users (ACCC 2001a).

\section{References}

Adams, W. J. and Yellen, J. L. 1976, 'Commodity bundling and the burden of monopoly', Quarterly Journal of Economics, vol. 90, pp. 475-98.

Albon, R., Hardin, A. and Dee, P. 1997, Telecommunications Economics and Policy Issues, Staff Information Paper, March, Industry Commission, AGPS, Canberra.

Australian Communications Authority 1999, Telecommunications Performance Report 1998-1999, AusInfo, Canberra.

Australian Competition and Consumer Commission 1999, Declaration of Local Telecommunications Services, Report, July, ACCC Publishing Unit, Canberra; available at http://www.accc.gov.au/telco/fstelecom.htm.

Australian Competition and Consumer Commission 2001a, Review of Price Control Arrangements, Draft Report, ACCC Publishing Unit, Canberra; available at http:// www.accc.gov.au.

Australian Competition and Consumer Commission 2001b, Summary of the Trade Practices Act 1974, ACCC Publishing Unit, Canberra; available at http:// www.accc.gov.au.

Bakos, Y. and Brynjolfsson, E. 1998, 'Bundling information goods: Pricing, profits and efficiency', Working Paper Series, MIT 
Sloan School of Management; available at http://www.gsm.uci.edu/ bakos and http:// ccs.mit.edu.erik.

Capon, N. and Kuhn, D. 1982, 'Can consumers calculate best buys?', Journal of Consumer Research, vol. 8, pp. 449-53.

Economides, N. 1993, 'Mixed bundling in duopoly', Working Paper EC-93-29, Stern School of Business, New York University; available at http://www.stern.nyu.edu/networks/papers.html.

Estelami, H. 1999, 'Consumer savings in complementary product bundles', Journal of Marketing Theory and Practice, vol. 7, no. 3, pp. 107-14.

Kahn, A. E. and Shew, W. B. 1987, 'Current issues in telecommunications regulation: Pricing', Yale Journal on Regulation, vol. 4, pp. 191-256.

Kephart, J. O., Das, R. and MacKie-Mason, J. K. 1999, 'Two-sided learning in an agent economy for information bundles'; available at http://www-personal.umich.edu/ jmm/ papers/bundle.pdf.

MacKie-Mason, J. K., Riveros, J. F. and Gazzale, R. S. 1999, 'Pricing and bundling electronic information goods: Field evidence'; available at http://www-personal.umich.edu/ $\sim$ jmm/papers.html.

Muir, J., Jennings, B. and McAnally, F. 1999, 'Price competition in Australian telecommunications', Agenda, vol. 6, pp. 111-26.

Nalebuff, B. 1999, 'Bundling', Working Paper no. 99-14, Yale International Center for Fi- nance, New Haven; available at http://papers.ssrn.com/paper.taf?abstract_id=185193.

Papandrea, F. Stoeckl, N. and Daly, A. 2000, 'Bundling of telecommunications services', Working Paper, Communications and Media Policy Institute, University of Canberra.

Productivity Commission 2001, Telecommunications Competition Regulation, Draft Report, Productivity Commission, Canberra; available at http://www.pc.gov.au

Russo, E. 1977, 'The value of unit price information', Journal of Marketing Research, vol. 14, pp. 193-201.

Schmalensee, R. 1982, 'Commodity bundling by single-product monopolies', Journal of Law and Economics, vol. 25, pp. 67-71.

Schmalensee, R. 1984, 'Gaussian demand and commodity bundling', Journal of Business, vol. 57, pp. 211-30.

Spence, A. M. 1976, 'Product selection, fixed costs and monopolistic competition', Review of Economic Studies, vol. 43, pp. 21735.

Spulber, D. F. 1995, 'Deregulating telecommunications', Yale Journal on Regulation, vol. 12, pp. 25-67.

Stigler, G. J. 1963, 'United States v. Loews's Inc.: A note on block-booking', Supreme Court Review, vol. 1, pp. 152-7.

Telecommunications Industry Ombudsman 2001, Annual Report 2001; available at http:/ /www.tio.com.au/publications/ annual_reports/. 